\title{
CORRECTION
}

\section{Correction to: Short-term mortality after primary and revision total joint arthroplasty: a single-center analysis of 103,560 patients}

\author{
Felix Prange ${ }^{1} \cdot$ Alina Seifert $^{1,3}$. Pongsiri Piakong ${ }^{2} \cdot$ Thorsten Gehrke $^{1} \cdot$ Dario Guttowski $^{1}$ - Sophia-Marlene Busch ${ }^{1}$. \\ Jochen Salber ${ }^{3} \cdot$ Mustafa Citak $^{1}$ (1)
}

Published online: 11 June 2021

(c) Springer-Verlag GmbH Germany, part of Springer Nature 2021

\section{Correction to: \\ Archives of Orthopaedic and Trauma Surgery (2021) 141:517-525 \\ https://doi.org/10.1007/s00402-020-03731-w}

The original version of this article unfortunately contained a mistake. Alina Seifert and Jochen Salber's affiliations was incorrect.

The correct affiliation should be:

Department of Surgery, Ruhr University Hospital, Bochum, Germany.

Publisher's Note Springer Nature remains neutral with regard to jurisdictional claims in published maps and institutional affiliations.

The original article can be found online at https://doi.org/10.1007/ s00402-020-03731-w.

Mustafa Citak

mustafa.citak@helios-gesundheit.de

1 Department of Orthopaedic Surgery, ENDO-Klinik Hamburg, Holstenstr. 2, 22767 Hamburg, Germany

2 Institute of Orthopaedics, Lerdsin Hospital, Bangkok, Thailand

3 Department of Surgery, Ruhr University Hospital, Bochum, Germany 